\title{
Review of: "Acute toxicity and health-related quality of life after accelerated whole breast irradiation in 5 fractions with simultaneous integrated boost"
}

\author{
Maria Carmen De Santis ${ }^{1}$ Riccardo Ray Colciago, Eliana La Rocca \\ 1 Fondazione IRCCS Istituto Nazionale dei Tumori di Milano
}

Potential competing interests: The author(s) declared that no potential competing interests exist.

With the advent of the FAST trials [1,2], there has been a growing interest in the use of ultrahypofractionation for the adjuvant treatment of breast cancers. Nevertheless, in daily clinical practice, there are still some concerns about its use. Your study is perfect timing, as it will empower evidence in the use of ultra-hypofractionation. Indeed, the YO-HAI5 trial will generate a level one evidence [3] by randomizing an experimental arm VS control arm which is considered the standard of care.

The present paper is the interim analysis of the YO-HAI5 trial,made to analyze physicians 'assessed acute toxicity and patient-related outcomes for Quality of Life reported in the first 200 randomized patients. In this commentary we are going to analyze this study from a clinical and methodological point of view following the PICO criteria [4].

Population is the first aspect to be checked. Eligible patients were women $>18$ years old, who underwent breast conservative surgery without any nodal or distant metastases and every case was discussed in a multidisciplinary tumor board.

Indeed, selection is well done and this sample of patients does represent the population that is encountered daily and, therefore, this study will be easily translated in clinical practice.

Intervention and Comparison are the next steps. The experimental arm is an ultra-hypofractionated treatment made of 28.5 Gydelivered in 5 fractions (5.7 Gy per fraction) to the whole breast every other day. The control arm is an hypofractionated schedule, as for START B trial [5], of 40.05 Gy delivered in 15 fractions (2.67 Gy per fraction) to the whole breast, daily.

From a methodological point of view, the procedure is correct as an experimental arm is compared to the standard one (as suggested by ASTRO guidelines [6]),

Furthermore, from a radiobiological point of view, using the Fowler formula for BED [7] the two treatments are equivalent. Using an alpha/beta parameter of 4.6 as suggested by the trial, indeed, $\mathrm{BED}_{4.6}$ of the experimental arm is $63.82 \mathrm{~Gy}$ and $\mathrm{BED}_{4.6}$ of the standard arm is $63.30 \mathrm{~Gy}$. Using an alpha/beta parameter of 3.7 as used for the FAST-forward trial, $\mathrm{BED}_{3.7}$ was $72.41 \mathrm{~Gy}$ and 68.95 Gy respectively.

Also, the patients 'setup and the centring computed tomography were done as per standard of care. 
Nevertheless, it is not described if treatments are delivered with a 3D conformal technique or with an Intensity Modulated technique.

Moreover, this study has the merit of clarifying one of the most controversial themes about the FASTForward trial: the use of the boost. The experimental arm prescribed 31 Gy in 5 fractions (6.2 Gy per fraction; $\mathrm{BED}_{4.6} 72.78 \mathrm{~Gy}$ ) the the tumor bed with a simultaneous integrated boost technique. The standard arm used the same technique to prescribe 46,8 Gy in 15 fractions (3.12 Gyper fraction; BED 4.6 78.54 Gy) to the tumor bed. Therefore, while in the FAST-Forward trial a boost of at least 4 fractions nearlydoubled the overall treatment time (and this was one of the most important criticism of this trial), in the YO-HAI5 a simultaneous integrated boost does not prolong the duration of therapy.

At last, treatment delivery in prone position could be criticized as it is not yet considered the standard of care. The most important concern involves interfractions changes that imply the use of daily CBCT to correct for rotational variations that occur in $20 \%$ of treatments as stated by Xiao et al [8].

Outcomes are the last point. The primary endpoint of the trial is breast retraction 2 years after RT. Secondary endpoints are acute breast toxicity, late toxicities other than breast retraction, fatigue, cosmesis, Quality of Life, cost effectiveness, locoregional and distant tumor control and dose/volume parameters of target and organs of risk.

The primary endpoint, so, is a late toxicity outcome. In the era of ultra-hypofractionation, toxicity is one of the biggest concerns for every radiation oncologist. This study will prove if these fears are founded or not. Nevertheless, 2 years for the late toxicity are few. The experience from previous trials $[1,2,5,9-11]$ shows that differences in toxicities between standard arms and experimental arms will occur in at least 5 years. Indeed, if no statistical differences will be detected between the two arms, it could be because of the insufficient time of follow-up.

Conversely, it is very interesting the analyses of the secondary endpoints as the focus is not only on the clinical or toxic outcomes but also on cost-effectiveness valuations and patients' perspective of their life after the treatment. Indeed, both physician-assessed toxicity and patient-reported outcome are evaluated, and the most common scales or questionnaire of evaluation were used to define these results.

Nevertheless, these endpoints were not prespecified for the statistical analyses. This means that, even if a statistically significant difference will be noticed between the two arms $(p<0.005)$ this could be clinically irrelevant. Therefore, evidence generated on the secondary outcomes, will be weak. At last, neither patients nor doctors are blinded, thus generating a detection and a performance bias.

Talking about this interim analysis of 200 patients, the results are strongly in favor of the experimental arm. Nonetheless this paper evaluates only the acute toxicities in terms of quality of life and cosmetic outcomes. This advantage is well predicted as the $\mathrm{BED}_{10}$ (for the acute toxicity) of the experimental arm is of 44.75 Gy VS BED 10 of the standard arm of $50.74 \mathrm{~Gy}$, i.e., less acutely toxic.

Therefore, the most important value of this interim analysis are the subjective outcomes that are shown to 
be significantly better for the experimental arms. Indeed, the fact that patients feel better about a shorter course of radiation therapy is predictable but not taken for sure.

In conclusion, as a radiation oncologist will approach this paper, he will read some expected results as well as the important patients' perspective. The completeness of the YO-HAI5 trial will give important information about the use of ultra-hypofractionated regimens in the adjuvant treatment of early breast cancer even if there are some limitations.

\section{References}

1. Brunt AM, Haviland JS, Sydenham M, Agrawal RK, Algurafi H, Alhasso A, Barrett-Lee P, Bliss P, Bloomfield D, Bowen J, Donovan E, Goodman A, Harnett A, Hogg M, Kumar S, Passant H, Quigley M, Sherwin L, Stewart A, Syndikus I, Tremlett J, Tsang Y, Venables K, Wheatley D, Bliss JM, Yarnold JR. Ten-Year Results of FAST: A Randomized Controlled Trial of 5-Fraction Whole-Breast Radiotherapy for Early Breast Cancer. J Clin Oncol. 2020 Oct 1;38(28):3261-3272. doi: 10.1200/JCO.19.02750. Epub2020 Jul 14. PMID: 32663119; PMCID: PMC7526720.

2. Murray Brunt A, Haviland JS, Wheatley DA, Sydenham MA, Alhasso A, Bloomfield DJ, Chan C, Churn M, Cleator S, Coles CE, Goodman A, Harnett A, Hopwood P, Kirby AM, Kirwan CC, Morris C, Nabi Z, Sawyer E, Somaiah N, Stones L, Syndikus I, Bliss JM, Yarnold JR; FAST-Forward Trial Management Group.

Hypofractionated breast radiotherapy for 1 week versus 3 weeks (FAST-Forward): 5-year efficacy and late normal tissue effects results from a multicentre, non-inferiority, randomised, phase 3 trial. Lancet. 2020 May 23;395(10237):1613-1626. doi: 10.1016/S0140-6736(20)30932-6. Epub 2020 Apr 28. PMID: 32580883; PMCID: PMC7262592.

3. Burns PB, Rohrich RJ, Chung KC. The levels of evidence and their role in evidence-based medicine. Plast ReconstrSurg. 2011 Jul;128(1):305-310. doi: 10.1097/PRS.0b013e318219c171. PMID: 21701348; PMCID: PMC3124652.

4. Methley AM, Campbell S, Chew-Graham C, McNally R, Cheraghi-Sohi S. PICO, PICOS and SPIDER: a comparison study of specificity and sensitivity in three search tools for qualitative systematic reviews. BMC Health Serv Res. 2014 Nov 21;14:579. doi: 10.1186/s12913-014-0579-0. PMID: 25413154; PMCID: PMC4310146.

5. START Trialists' Group, Bentzen SM, Agrawal RK, Aird EG, Barrett JM, Barrett-Lee PJ, Bentzen SM, Bliss JM, Brown J, Dewar JA, Dobbs HJ, Haviland JS, Hoskin PJ, Hopwood P, Lawton PA, Magee BJ, Mills J, Morgan DA, Owen JR, Simmons S, Sumo G, Sydenham MA, Venables K, Yarnold JR. The UK Standardisation of Breast Radiotherapy (START) Trial B of radiotherapy hypofractionation for treatment of early breast cancer: a randomised trial. Lancet. 2008 Mar 29;371(9618):1098-107. doi: 10.1016/S0140-6736(08)60348-7. Epub 2008 Mar 19. PMID: 18355913; PMCID: PMC2277488.

6. Smith BD, Bellon JR, Blitzblau R, Freedman G, Haffty B, Hahn C, Halberg F, Hoffman K, Horst K, Moran J, Patton C, Perlmutter J, Warren L, Whelan T, Wright JL, Jagsi R. Radiation therapy for the whole breast: 
Executive summary of an American Society for Radiation Oncology (ASTRO) evidence-based guideline. Pract Radiat Oncol. 2018 May-Jun;8(3):145-152. doi: 10.1016/j.prro.2018.01.012. Epub2018 Mar 12. PMID: 29545124.

7. Fowler JF. 21 years of biologically effective dose. Br J Radiol. 2010 Jul;83(991):554-68. doi: 10.1259/bjr/31372149. PMID: 20603408; PMCID: PMC3473681.

8. Xiao A, Jutzy J, Hubert G, Edens M, Washington M, Hasan Y, Chmura SJ, Al-Hallaq HA. A study of the dosimetric impact of daily setup variations measured with cone-beam CT on three-dimensional conformal radiotherapy for early-stage breast cancer delivered in the prone position. J Appl Clin Med Phys. 2020 Dec;21(12):146-154. doi: 10.1002/acm2.13080. Epub 2020 Oct 30. PMID: 33124774; PMCID: PMC7769386. 9. START Trialists' Group, Bentzen SM, Agrawal RK, Aird EG, Barrett JM, Barrett-Lee PJ, Bliss JM, Brown J, Dewar JA, Dobbs HJ, Haviland JS, Hoskin PJ, Hopwood P, Lawton PA, Magee BJ, Mills J, Morgan DA, Owen JR, Simmons S, Sumo G, Sydenham MA, Venables K, Yarnold JR. The UK Standardisation of Breast Radiotherapy (START) Trial A of radiotherapy hypofractionation for treatment of early breast cancer: a randomised trial. Lancet Oncol. 2008 Apr;9(4):331-41. doi: 10.1016/S1470-2045(08)70077-9. Epub 2008 Mar 19. PMID: 18356109; PMCID: PMC2323709.

10. Whelan TJ, Pignol JP, Levine MN, Julian JA, MacKenzie R, Parpia S, Shelley W, Grimard L, Bowen J, Lukka H, PereraF, Fyles A, Schneider K, Gulavita S, Freeman C. Long-term results of hypofractionated radiation therapy for breast cancer. N Engl J Med. 2010 Feb 11;362(6):513-20. doi: 10.1056/NEJMoa0906260. PMID: 20147717.

11. Offersen BV, Alsner J, Nielsen HM, Jakobsen EH, Nielsen MH, Krause M, Stenbygaard L, Mjaaland I, Schreiber A, Kasti UM, Overgaard J; Danish Breast Cancer Group Radiation Therapy Committee. Hypofractionated Versus Standard Fractionated Radiotherapy in Patients With Early Breast Cancer or Ductal Carcinoma In Situ in a Randomized Phase III Trial: The DBCG HYPO Trial. J Clin Oncol. 2020 Nov 1;38(31):3615-3625. doi: 10.1200/JCO.20.01363. Epub2020 Sep 10. PMID: 32910709. 